\title{
Matematik Okuryazarlığı Soru Yazma Sürecinde Yer Alan Eylemlerin Belirlenmesi ve Sıralarının Kestirilmesi
}

\author{
Furkan Demir
}

Makale Geliş Tarihi:05.11.2019

Makale Kabul Tarihi: 11.12.2019

DOI: $10.35675 /$ befdergi.643469

$\ddot{\boldsymbol{O}} z$

Bu çalışma, matematik okuryazarlı̆̆ soru yazma sürecinde yer alan eylemleri ve bu eylemlerin süreçte sıklıkla nasıl sıralandiğını belirlemeyi amaçlamaktadır. Bu amaçla iki aşamalı bir yöntem uygulanmıştır. Birinci aşamada 47, ikinci aşamada 65 ilköğretim matematik öğretmen adayının 3-6 kişilik gruplar halinde yürüttüğ̈̈ soru yazma süreçleri incelenmiştir. Birinci aşamada, raportör ögretmen adaylarının kendi gruplarındaki her bir soru yazma sürecini aktardıkları kompozisyonlar içerik analizine tabi tutularak süreçte yer alan eylemler belirlenmiştir. Bu eylemlerden Süreç Takip Formu oluşturulmuştur. İkinci aşamada, raportör ögretmen adaylarının kendi gruplarındaki soru yazma süreçlerini aktardıkları Süreç Takip Formlarının betimsel analizi yapılarak süreçte yer alan eylemlerin siklıkla nasıl sıralandığ belirlenmiştir. Bu siralamalar süreç şemalarl şeklinde bulgularda sunulmuştur. Bu şemalar sistematik bir soru yazma süreci geliştirilmesine ilişkin bir ilk adım olarak görülebilir. Sistematik soru yazma süreçleri ögretmen ve ögretmen adaylarının bu konuda daha hızl deneyim kazanmalarına ve problem yazmada yaşadıkları güçlüklerin azaltılmasına katkı sağlayabilir.

Anahtar Kelimeler: Bağlamsal problemler, matematik okuryazarlığı, ögretmen adayları, soru yazma süreci

\section{Determining the Actions of the Problem Posing Process in Mathematical Literacy and Estimating Their Order}

\begin{abstract}
This study aimed to determine the actions involved in the problem posing process in mathematical literacy and how these actions were frequently ordered in the process. For this purpose, a two-stage method was adopted. In the first stage 47, in the second stage 65, primary school math teacher candidates' problem posing processes were examined as they managed groups of 3-6. For the first stage, the compositions where reporter teacher candidates cited each problem posing process in their own groups were subjected to a content analysis and the actions in the process were determined. A process Monitoring Form was created from these actions. In the second stage, the descriptive analysis of the Process Monitoring Forms in which reporter teacher candidates cited their problem posing processes in their own groups was carried out and it was determined how the actions in the process were frequently ordered. These orders were presented in the findings as the form of process charts. These charts can be seen as the first step to develop a systematic process for posing problems. Systematic problem posing processes can help teachers and teacher candidates gain experience faster on this matter and reduce the difficulties they have in posing problems.
\end{abstract}

\footnotetext{
* Kütahya Dumlupınar Üniversitesi, Eğitim Fakültesi, Matematik ve Fen Bilimleri Eğitimi Bölümü, Kütahya, Türkiye, furkan.demir@dpu.edu.tr, ORCID: 0000-0003-3740-8088

Kaynak Gösterme: Demir, F. (2019). Matematik okuryazarlığı soru yazma sürecinde yer alan eylemlerin belirlenmesi ve siralarının kestirilmesi. Bayburt Eğitim Fakültesi Dergisi, 14(28), 372-390. https://doi.org/10.35675/befdergi.643469
} 
Keywords: Contextual problems, mathematics literacy, teacher candidates, problem posing process

\section{Giriş}

Matematik öğretmen adaylarının matematik problemi yazmada güçlük çektikleri ve dikkatlerinin problem yazmaya hiç çekilmemiş olması hâlinde sınıflarında iyi problemler ortaya koymakta sorun yaşayacakları ifade edilmektedir (Stickles, 2011). Matematik öğretmenleri, öğrencilerini matematiksel düşünmeye teşvik etmek (Crespo, 2003) ve onların matematik anlayışları hakkında derinlemesine bilgi sahibi olabilmek için (Vacc, 1993; Cai ve Hwang, 2002; Goldenberg ve Walter, 2003) öğrencilerinin mücadele edecekleri problemler ortaya koyabilmelidir. Problem yazmak öğretmenlerin işinin önemli bir parçasıdır (Patáková, 2013) ve matematik eğitiminde önemli bir yere sahiptir. Matematik öğretmen adayları matematiksel düşünce ile iç içe olan bir birey grubunu temsil eder. Adaylar bir yandan matematik kavramları ve matematiksel düşünme hakkında daha derinlemesine bir anlayış geliştiren matematik ögrencileridir, bu nedenle problem yazma, yeni bir etkinlikle matematiği deneyimleme firsatı sunar. Diğer yandan, okullardaki çocuklara matematiği öğretmek için eğitilen bireylerdir, bu nedenle problem yazmaya çalışmak, öğrencileri için matematiksel problemleri nasıl oluşturabilecekleri hakkında düşünmelerini sağlar (Silber ve Cai, 2017). Problem yazma etkinliklerinin matematik eğitimine dâhil edilmesi gerektiği belirtilmekte ve öğrencilerin önceden çözdükleri diğer problemlerden ortaya çıkan tecrübelerinden yararlanarak kendilerine ait problemler yazmaları tavsiye edilmektedir (National Council of Teachers of Mathematics [NCTM], 1991; NCTM, 2000). Matematiksel olarak yeterli olan öğrencilerin "ilgili dış matematik kaynaklarını tanımlayabilmeleri ve bunları problem yazmak ya da çözmek için kullanmaları” gerektiği ileri sürülmektedir (National Governors Association Center for Best Practices and Council of Chief State School Officers [NGA], 2010). Alan yazında yer alan bu öngörüler, sonuçlar ve öneriler iki hususa dikkat çekmektedir. Birincisi, matematik eğitiminde ve öğretmen eğitiminde matematik problemi yazmanın önemi, ikincisi öğretmen ve/veya öğretmen adaylarının problem oluşturmada güçlük çektikleri hususudur. $\mathrm{Bu}$ iki husus, araştırmacıları problem yazma sürecini ve bu süreci etkileyen faktörleri incelemeye yöneltmiştir.

Stoyanova ve Ellerton (1996) serbest, yarı yapılandırılmış ve yapılandırılmış olmak üzere üç çeşit problem yazma durumu tanımlamıştır. Serbest durumlarda, bireylerden açık matematiksel bir durum için problem oluşturmaları istenmektedir (vanHarpen ve Sriraman, 2013). Yarı yapılandırılmış durumlar, serbest durumlardan daha ayrıntılı bilgiler içermekte ve bireylerden bu durumun yapısını keşfetmeye ve bunu önceki matematiksel deneyimlerinden edindiği bilgi, beceri, kavram ve ilişkileri uygulayarak tamamlamaları istenmektedir. (Yuan ve Sriraman, 2011). Yapılandırılmış durumlar, bireylerin belirli bir duruma dayanarak matematiksel problemler ortaya koymasını ve çözümün önceden belirlenmiş işlemlerle 
eşleşmesini gerektirir. Bu üç durum, problem yazma sürecinin nasıl başlatılacağı ile ilgilidir.

Pelczer ve Gamboa (2009) beş aşamalı (birbirinden ayrıştırılması ve sıralanması şart olmayan) bir problem yazma modeli önermiş̧ir: $\mathrm{Bu}$ model; kurulum, dönüşüm, formülasyon, değerlendirme ve son değerlendirme aşamalarını içermektedir. Yazarlar yaptıkları çalışmada, modellerini bu konuda hiçbir deneyimi olmayan ve deneyimli olan bireylerin problem yazma süreçlerini karşılaştırmak için kullanmıştır. Sonuç olarak deneyimli problem yazarlarının diğerlerine göre farklı yollar izlediğini belirlemiştir.

Patáková (2013) problem yazma sürecinde yürütülen eylemleri (i) denemeyanılma, (ii) kısmen kasıtlı ve (iii) kasıtlı olmak üzere üç kategoride ele almıştır. Deneyimsiz grupta deneme-yanılma eylemlerine daha sık rastlandığını, bu eylemler sırasında katılımcıların bir fikirden çabuk vazgeçip bir başka fikre yöneldiğini tespit etmiştir. $\mathrm{Bu}$ durumu deneyimsiz grubun fikirleri dönüştürmeye teşebbüs etmeden attığı, doğrusal bir problem yazma süreci olarak ifade etmiştir. Deneyimli olanların ise bu süreçte fikirlerinden diğer grup kadar kolay vazgeçmediklerini, bazen başlangıçtaki deneme-yanılma fikirlerine geri döndüklerini, bu durumda geliştirilebilecek ilginç problemler üzerine düşündüklerini ve kendi hatalarından ders aldıklarını tespit etmiştir. Kısmen kasıtlı ve kasıtlı eylemlere deneyimli grupta daha sık rastlandığını ifade etmiştir. Kasıtlı fikirleri birer dönüşüm olarak ele aldığ 1 çalışmasında, deneyimli grubun döngüsel bir problem yazma süreci izlediğini belirlemiştir. Ayrıca çalışmasının bulgularının tümünün Pelczer ve Gamboa'nın (2009) modelinde bir karşılığının olduğunu belirlemiştir.

$\mathrm{Bu}$ alanda yapılmış çalışmalara rağmen öğretmenlerin matematik problemi yazma sürecinde nelere odaklandıkları henüz açık değildir (Stickles, 2011). Problem yazma sürecinin nasıl işlediğine ve bu süreci etkileyen faktörlere ilişkin henüz sınırlı düzeyde bilgi bulunmaktadır (Silber ve Cai, 2017). Bu noktadan hareketle bu çalışmada matematik öğretmen adaylarının problem yazma süreçleri incelenmiştir. Çalışmanın sonunda, adaylar tarafindan problem yazma sürecinde yürütülen eylemlerin ve bunların sıklıkla hangi sıra ile takip edildiğinin belirlenmesi amaçlanmıştır. Diğer bir ifadeyle bu çalışmada, adayların yürüttüğü sistematik problem yazma süreçlerinin olup olmadığının ortaya konması hedeflenmiştir. Sistematik süreçler daha nitelikli problem yazma etkinliklerinin geliştirilmesine ve öğretmen adaylarının problem yazmada karşılaştıkları güçlükleri azaltmaya katkı sağlayabilir. Ayrıca, bu çalışmada elde edilen sistematik süreçlerin rehberliğinde gelecekte yapılacak çalışmalarda, problem yazma konusunda deneyimsiz olsalar dahi öğretmen adaylarının kasıtlı (hedefe yönelik) eylemlere daha fazla yer vermeleri ve daha hızlı deneyim kazanmaları sağlanabilir.

Matematik okuryazarlığ problemleri, matematik problemlerinin bir alt kümesidir ve bu alanda problem yazma sürecinin incelendiği az sayıda çalışma bulunmaktadır. Matematik okuryazarlı̆̆ 
çeşitli şekillerde formüle etme, uygulama ve yorumlamada kullanma kapasitesi olarak tanımlanmaktadır (Organisation for Economic Co-Operation and Development [OECD], 2013; OECD, 2016). Matematik okuryazarlığının tanımı gereği, problemler gerçek yaşamdan bağlamlar içinde sunulmaktadır. Öğretmen adayları "kendi yaşadıkları bir olayı/durumu soru olarak yazmayı" (Demir ve Altun, 2018) ve "günlük yaşamda gelişen olayları gözleyerek soru yazmayı" (Demir, Altun, Köse, 2018) matematik problemi yazma sürecinde bir firsat olarak nitelendirmiştir. Ayrıca bu durumların, öğretmen adaylarının problem yazmaya karşı ilgilerini artırdığı belirtilmiştir. Problem yazma alanındaki boşluğun giderilmesine katkı sağlamanın yanı sıra söz konusu firsatların öğretmen adaylarının problem yazmada karşılaştıkları güçlükleri azaltabileceği ve problem yazmaya karşı ilgilerini artırabileceği düşüncesiyle bu çalışmada öğretmen adaylarından matematik okuryazarlığı problemleri yazmaları istenmiştir.

Çalışmanın özellikle matematik okuryazarlı̆̆ problemlerine odaklanmasının başka nedenleri de vardır. Matematik okuryazarlığı, matematiğin gerçek yaşamdaki rolünü anlamak ve karşılaşılan sorunların çözümünde matematiği kullanabilmektir (McCrone ve Dossey, 2007). Öğretmen adaylarının matematik okuryazarlığı problem yazma sürecini yürütmelerinin, kendilerinin matematik ile gerçek yaşam arasındaki ilişkiyi fark etmelerine ve gelecekte öğrencilerine bu ilişkiyi fark ettirmelerine katk1 sağlayacağı düşünülmüştür.

\section{Çalışmanın Amacı}

$\mathrm{Bu}$ çalışmanın iki amacı bulunmaktadır. Birincisi, matematik okuryazarlığı soru yazma sürecinde yer alan eylemleri belirlemektir. İkincisi bu eylemlerin süreçte sıklıkla nasıl sıralandığını tespit etmektir. Bu amaçlar doğrultusunda araştırmanın problemleri şu şekilde ifade edilebilir:

1. Matematik öğretmen adaylarının matematik okuryazarlığı problemi yazma sürecinde yer alan eylemler nelerdir?

2. Matematik öğretmen adaylarının matematik okuryazarlığı problemi yazma sürecinde yer alan eylemler sıklıkla nasıl sıralanmaktadır?

\section{Yöntem}

$\mathrm{Bu}$ çalışmanın amacı matematik okuryazarlığı soru yazma sürecinde yer alan eylemleri ve bu eylemlerin sıklıkla nasıl bir sıra ile takip edildiğini belirlemektir. Amaca ulaşmak için yapılan çalışmalar iki aşamadan oluşmaktadır. Bu aşamaların işletilmesinde nitel araştırma yöntemleri kullanılmıştır.

Nitel araştırmalar; gözlem, görüş̧e ve doküman analizi gibi nitel veri toplama yöntemlerinin kullanıldığı, algıların ve ortamların doğal ortamında gerçekçi ve bütüncül bir şekilde ortaya konmasına yönelik nitel süreçlerin izlendiği çalışmalar 
olarak tanımlanmaktadır (Yıldırım ve Şimşek, 2008, 39). Ayrıca, içerik analizi nitel bir veri analizi yöntemidir. Bu çalışmada, birinci aşamada katılımcıların soru yazma süreçlerini aktardıkları kompozisyonlar birer doküman, bunların içerik analizine tâbi tutulması ile elde edilen ve ikinci aşamada kullanılan Süreç Takip Formları birer gözlem aracıdır. Bu nedenle bu araştırma için nitel yöntem uygun düşmektedir. Araştırmanın yöntemi Tablo 1'de özetlenmiştir.

Tablo1.

Araştırmanın Yöntemi

\begin{tabular}{cccccc}
\hline & Amaç & Model & Yöntem & Veri Toplama & Analiz \\
\hline 1 & Eylemlerin Belirlenmesi & Tarama & Nitel & $\begin{array}{c}\text { Gözlem / } \\
\text { Kompozisyonlar }\end{array}$ & $\begin{array}{c}\text { İçerik } \\
\text { Analizi }\end{array}$ \\
& & & Nitel & Gözlem / Süreç Takip & Betimsel \\
& $\begin{array}{c}\text { Eylemlerin Sırasının } \\
\text { Kestirilmesi }\end{array}$ & Tarama & & Formu & \\
\hline
\end{tabular}

Durum çalışması, sınırlı bir sistemin nasıl işlediğine ilişkin sistematik bilgi toplamak için birden çok veri toplama yöntemi kullanılarak o sistemin derinlemesine incelenmesini içeren metodolojik bir yaklaşımdır (Chmiliar, 2010). Durum çalışmalarında olayların ve davranışların kategorilerinin tanımlanması amaçlanır. (Hancock\&Algozzine, 2006). Bu çalışmada öğretmen adaylarının bilişsel ve duyuşsal birikimleri (matematiksel içerik bilgisi, gerçek yaşamdan deneyimleri, gruptaki akranları ile iletişimi, vb), problem yazma süreci ve sürecin bir çıktısı olarak elde ettiği matematik okuryazarlığı problemleri, sınırlı bir sistemin elemanları olarak düşünülebilir. $\mathrm{Bu}$ süreçteki eylemlerin tanımlanması da bu araştırmanın amacıdır. O hâlde bu araştırma nitel bir durum çalışması olarak tanımlanabilir.

\section{Çalışma Grubu}

Bu çalışmada birinci aşamada elde edilen eylemlerin, ikinci aşamada sıklıkla nasıl sıralandığı belirleneceğinden, birbirine benzer özellikler taşıyan iki çalışma grubuna yer verilmiştir. Yöntemin birinci aşamasında yer verilen grup "birinci çalışma grubu", ikinci aşamasında yer verilen grup "ikinci çalışma grubu" olarak adlandırılmıştır.

Birinci çalı̧̧ma grubu, Ege Bölgesinde yer alan bir devlet üniversitesinin 20162017 eğitim öğretim yılında İlköğretim Matematik Öğretmenliği lisans programında 3. sınıfa kayıtlı 47 öğretmen adayından oluşturulmuştur. İkinci çalışma grubu, 2018-2019 eğitim öğretim yılında aynı programda 2. ve 3. sınıfa kayıtlı 65 öğretmen adayından oluşturulmuştur. Birinci ve ikinci çalışma grubunda ortak (her iki grupta da yer alan) katılımcı bulunmamaktadır. 


\section{Veri Toplama Araçları ve Verilerin Toplanması}

Araştırmanın verileri yukarıda belirtilen öğretim yıllarında açılan seçmeli derslerde (haftada 2 saat) toplanmıştır. Uygulamalarda öğretmen adaylarından, problemlerin bağlamını oluştururken PISA (Program for International Student Assessment) tarafından belirlenen dört kategoriden (kişisel, mesleki, toplumsal, bilimsel) faydalanarak çözümünde matematiksel bilgi veya yöntemlere ihtiyaç duyulan ve hayatta karşılaştıkları ya da karşılaşılması muhtemel olayları/durumları örneklemeleri ve bunlar üzerinden matematik okuryazarlığı problemleri üretmeleri istenmiştir. Bu koşullar, soru yazma sürecinin başlangıcı dışında, Van Harpen ve Sriraman (2013) tarafından ifade edilen serbest koşullarla örtüşmektedir. Aradaki fark, serbest koşullarda başlangıçta açık matematiksel bir durum (konu, nesne) verilirken bu çalışmada problem yazarlarının bu konuda da özgür bırakılmış olmasidir.

Araştırmanın yöntemine bakıldığında ilk sırada, matematik okuryazarlığ problemi yazma sürecinde yer alan eylemlerin belirlenmesi yer almaktadır. $\mathrm{Bu}$ amaçla birinci çalışma grubu ile yürütülen ve 7 hafta süren matematik okuryazarlığı öğretiminin problem yazmayı içeren son 3 haftasında katılımcıların problem yazma süreçleri incelenmiştir. Katılımcıların 3-6 kişilik gruplar hâlinde derste problem yazdıkları bu süreçte her gruptan bir öğretmen adayı raportör olarak görevlendirilmiştir. Raportörün görevi problem yazma sürecinde yürütülen eylemleri ve gerçekleşen konuşmaları kompozisyon şeklinde yazılı olarak kaydetmek ve yazılan her bir problem için araştırmacıya bu kayıtları içeren bir rapor teslim etmektir. Toplanan bu raporlar analiz edilerek ikinci aşamada kullanılacak olan Süreç Takip Formu oluşturulmuştur. Süreç Takip Formu Verilerin Analizinde sunulmuştur.

Yöntemin ikinci aşamasında, Süreç Takip Formunda yer alan eylemlerin soru yazma sürecinde nasıl sıralandığını belirleme işlemi yer almaktadır. Bunun için ikinci çalışma grubu ile yürütülen ve 13 hafta süren matematik okuryazarlığ öğretiminin problem yazmayı içeren son 5 haftasında katılımcıların problem yazma süreçleri incelenmiştir. Katılımcıların 3-5 kişilik gruplar hâlinde problem yazdıkları bu süreçte her bir gruptan bir öğretmen adayı raportör olarak görevlendirilmiştir. Raportörün görevi Süreç Takip Formunda yer alan eylemlerin, kendi gruplarında yürütülen problem yazma sürecinde hangi sıra ile takip edildiğini bu forma kaydetmek ve yazılan her bir problem için araştırmacıya bir Süreç Takip Formu teslim etmektir.

Toplanan verilerin güvenirliğini artırmak için Süreç Takip Formunun nasıl doldurulması gerektiğine ilişkin açıklamalara bir ders saati ayrılmıştır. Bunun yanı sıra formun üst kısmında, nasıl doldurulacağına ilişkin açıklamalara yer verilmiştir. Öğretmen adaylarından Süreç Takip Formundaki eylemlere sıra numaraları vermeleri istenmiştir. Her eyleme bir sıra numarası vermek zorunlu değildir. İlgili problemi yazdıkları süreçte hangi eylemlere yer verdilerse sadece onlara sıra 
numarası vermeleri, diğerlerini boş bırakmaları istenmiştir. Eğer süreçte yer verdikleri eylem Süreç Takip Formundaki hiçbir cümleye karşılık gelmiyorsa onu da formda boş bırakılan kutuya kendi cümleleriyle ifade etmeleri ve ilgili kutucuğa sıra numarası vermeleri istenmiştir. Bu aşamada öğretmen adaylarından 64 adet Süreç Takip formu toplanmıştır. Bunlardan 20 tanesi yazılan problemin matematik okuryazarlığı sorusu olma ölçütünü sağlamaması veya forma özensiz veri girişi yapıldığının tespit edilmiş olması nedenlerinden dolayı analiz dışı bırakılmıştır. Kalan 44 adet problem ve bunların Süreç Takip Formu analiz edilerek eylemlerin sıklıkla hangi sıraya göre ilerlediği incelenmiştir.

\section{Verilerin Analizi}

Birinci çalışma grubundan toplanan kompozisyonlar, öğretmen adaylarının problem yazma sürecinde yer verdikleri eylemleri ortaya çıkaracak şekilde içerik analizine tâbi tutulmuş ve gruplandırılmıştır. Güvenirliğin artırılması için bu işlemler araştırmacı ve bir ölçme değerlendirme uzmanı tarafından yapılmış, farklılıklar üzerine tartışma ve uzlaşma yoluyla sonuçlar elde edilmiştir. Analiz ve gruplama sonucunda toplam 9 eylem cümlesi elde edilmiştir. Bu cümlelerle Süreç Takip Formu oluşturulmuştur. Bu eylemler aynı zamanda bu araştırmanın birinci sorusuna karşılık gelen bulgulardır. Bu yüzden Süreç Takip Formu ile ilgili detaylara bulgularda yer verilmiştir.

İkinci çalışma grubundan toplanan Süreç Takip Formlarının analiz süreci aşağıda sırasıyla açıklanmıştır.

1. Her bir eylem cümlesi bir harfle eşleştirilmiştir. Artık tüm formlarda o eylem cümlesi, eşleştirildiği harfle temsil edilmiştir. Her bir harf bir durak olarak tanımlanmıştır. Buna göre Şekil 1'de verilen örnek formdan elde edilen problem yazma süreci,

\begin{tabular}{|c|c|c|c|c|c|c|c|c|c|c|c|}
\hline Durak Sira No: & 1 & 2 & 3 & 4 & 5 & 6 & 7 & 8 & 9 & 10 & 11 \\
\hline Durak & D & I & A & E & B & C & G1:EVT & J & H & F1:EVT & K \\
\hline
\end{tabular}

şeklinde 11 duraklı bir kod olarak işlenmiştir. Tüm formlarda yer alan veriler bu şekilde işlenmiştir. Burada I, D’ye göre; A da I'ya göre (her durak kendinden önceki durağa göre) varış durağı olarak tanımlanmıştır. 


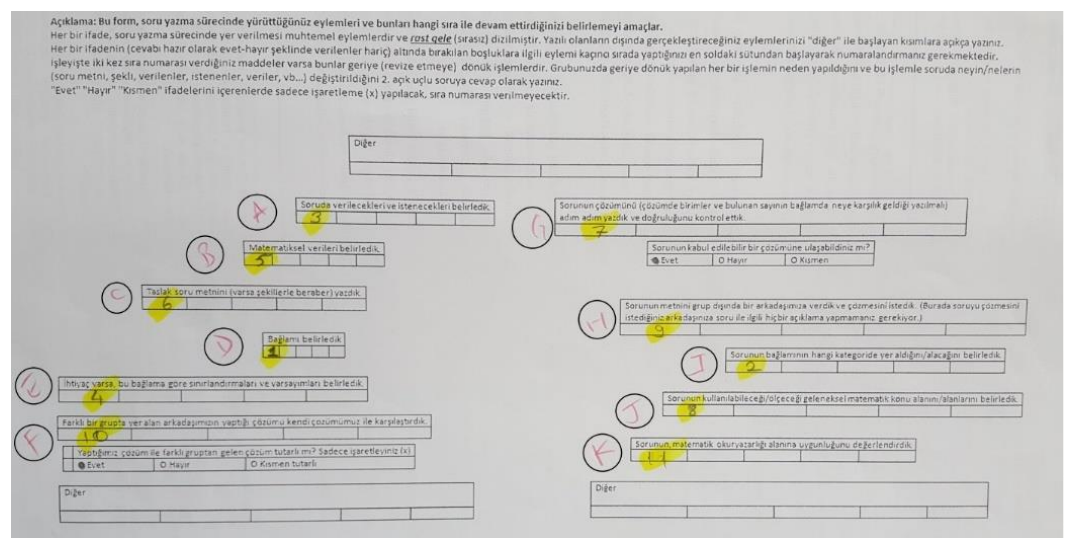

Şekil 1. Analiz edilen örnek bir süreç takip formu

2. Her bir duraktan diğerlerine kaç kez (tekrar sayısı) geçiş yapıldığı ve varış durağının kaçıncı sırada olduğu belirlenmiştir.

a. Tekrar sayıları, art arda en sik tercih edilen durakların belirlenmesini sağlamıştır.

b. Varış duraklarının sıra ortalamaları hesaplanmıştır. Varış duraklarının sıra ortalamalarına bakılarak durakların öncelik sırası kestirilmeye çalışılmıştır. Buradaki ölçüt, sıra ortalaması küçük olan durağın bir problem yazma sürecinde diğer duraklara göre daha önce gelme olasılığının daha yüksek olacağıdır.

3. Veri girişinin güvenirliği,

a. Toplam geçiş sayısı ile, her bir durağa varış ve her bir duraktan gidiş sayılarının eşit olduğunu gösteren Tablo 3 ve Tablo 4 aracılı̆̆ıyla,

b. Değerlendirilen Süreç Takip Formu sayısı ile ilk ve son durak sayılarının eşit olduğunu gösteren Tablo 4 aracılığıyla kanıtlanmıştır.

Tüm bu işlemler sonucunda; öğretmen adaylarının matematik okuryazarlığı problemi yazmaya genellikle hangi eylemle başlamayı tercih ettiklerine, art arda hangi eylemlere ne siklıkta yer verdiklerine ve süreci hangi eylemlerle sonlandırdıklarına ilişkin bulgular elde edilmiştir. Ayrıca eylemlerin tekrar sayıları (sıklık) ve sıra ortalamalarından yararlanılarak matematik okuryazarlığı problem yazma süreç şemaları oluşturulmuştur.

\section{Bulgular ve Yorum}

Aşağıda araştırmanın bulguları çalışmanın alt problemlerinin sırasına göre verilmiştir. Birinci alt problem öğretmen adaylarının matematik okuryazarlığı 
problemi yazarken gerçekleştirdiği eylemlerin belirlenmesi ile ilgiliydi. Yöntemin ilk aşamasında birinci çalışma grubunun raportörlerinden toplanan kompozisyonlardan örnek cümleler ve bunların içerik analizi sonuçlarından elde edilen kategoriler Tablo 2'de sunulmuştur.

Tablo 2.

Kompozisyonlardan Örnekler ve Kategorileri

\begin{tabular}{|c|c|c|}
\hline Veri & Bulgu & Kategori \\
\hline \multirow{10}{*}{ G2-3 } & Bağlamımızı kişisel bağlam olarak belirledik. & $\mathrm{I}$ \\
\hline & $\begin{array}{l}\text { Bu bağlamdan yolculuk konusunu seçerek ulaşım araçlarından taksiyi ele } \\
\text { aldık }\end{array}$ & $\mathrm{D}$ \\
\hline & $\begin{array}{c}\text { Verilerimizi sabit bir parasal değer ve parasal artış gösteren iki farklı değer } \\
\text { olarak sınıflandırdık. }\end{array}$ & $\mathrm{E}$ \\
\hline & $\begin{array}{c}\text { Gidilen yol, yolda beklenen zaman, zamana bağlı sabit oranlı artış } \\
\text { gösterirken, taksimetre açılışının tek değişkeni taksi sayısı olan sabit değer } \\
\text { olarak belirledik. }\end{array}$ & $\mathrm{B}$ \\
\hline & $\begin{array}{l}\text { Verilerimizi soruda tablo şeklinde göstermeye karar verdik. Tüm bunları ele } \\
\text { alarak, bizi bulduğumuz üç çözüm yoluna götürecek, basitten karmaşığa } \\
\text { kolaydan zora doğru üç soru yazdık. }\end{array}$ & $\mathrm{C}$ \\
\hline & $\begin{array}{l}\text { Bu soruların her bir çözüm basamağını açık ve net bir şekilde yazmaya özen } \\
\text { göstererek sorularımızı çözdük. }\end{array}$ & G \\
\hline & $\begin{array}{c}\text { Daha sonra bu üç çözüm yolunu mukayese edebilmek adına bir durum } \\
\text { belirterek bulduğumuz sayısal değerleri yorumlamak ve bu problemleri en } \\
\text { faydalı (işlevsel sonuçları olacak şekilde) şekilde çözüme kavuşturmak için } \\
\text { dördüncü soruyu yazdık. }\end{array}$ & $\mathrm{C}$ \\
\hline & $\begin{array}{l}\text { Yorumlanan değerlerin hangi durumlarda hangi yolun seçilmesinin daha } \\
\text { uygun olduğuna karar vermemizi sağlayıp sağlamadığını kontrol ettik. }\end{array}$ & G \\
\hline & $\begin{array}{l}\text { Sorumuzun anlatmak ve sormak istediğimiz şekilde olup olmadığına emin } \\
\text { olmak icin arkadaslarımızdan sorumuzu cözmelerini rica ettik. }\end{array}$ & $\mathrm{H}$ \\
\hline & $\begin{array}{l}\text { Karşılaştığımız çözümlerin beklediğimiz çözümlerle denk olduğunu gördük } \\
\text { ve böylece sorumuzu tamamladık. }\end{array}$ & $\mathrm{F}$ \\
\hline G1-8 & $\begin{array}{l}\text { Bir arazide hem ev yapılmasını hem de (yeşil alan için) kullanılabilecek bir } \\
\text { alan bırakılmasını gerektiren bir problem oluşturdum. Matematiksel olarak } \\
\text { arazinin çevresini verip evin çevresini bulmasını istedim. }\end{array}$ & $\mathrm{A}$ \\
\hline \multirow{3}{*}{ G1-2 } & $\begin{array}{c}\text { Yazın bir arkadaşımla gitmeyi düşündüğümüz festivale, evden mi gelsek } \\
\text { daha az para harcarız, pansiyonda kalarak mı diye düşünürken böyle bir } \\
\text { problem yazmaya karar verdim. }\end{array}$ & $\mathrm{D}$ \\
\hline & $\begin{array}{c}\text { Yol masrafı, pansiyon ve yemek masraflarını araştırıp problem için bilgi } \\
\text { topladım. }\end{array}$ & $\mathrm{B}$ \\
\hline & $\begin{array}{c}\text { Kafamdaki soruyu probleme (yazıya) taşıyarak ilkokul öğrencilerinin } \\
\text { çözebileceği bir formata getirdim... }\end{array}$ & $\mathrm{C}$ \\
\hline
\end{tabular}

Tablo 2'de tüm kompozisyonların incelenmesiyle elde edilen 9 kategorinin (eylem cümlesinin) tümünü içeren 3 örnek kompozisyondan ifadelere yer 
verilmiştir. Diğer kompozisyonlardaki tüm ifadeler Tablo 1'de verilen kategorilerden biri ile eşleşmektedir. Bu kategoriler aşağıda sırasız olarak (Süreç Takip Formunda verildiği gibi, rastgele) dizilmiştir. Eylemlerin sıralanması işlemi araştırmanın ikinci sorusudur ve orada incelenmiştir.

A: Soruda verilecekleri ve istenecekleri belirlemek

B: Matematiksel verileri belirlemek

C: Taslak soru metnini (varsa şekille beraber) oluşturmak

D: Bağlamı belirlemek

E: İhtiyaç varsa, bağlama göre sınırlandırmaları ve varsayımları belirlemek

F: Farklı gruptan birinin çözümü ile soru yazarlarının çözümünü karşılaştırmak

G: Sorunun çözümünü adım adım yazmak ve doğruluğunu kontrol etmek

H: Soru metnini grup dişında birine vererek (ona soru ile ilgili hiçbir açıklama yapmadan) çözmesini istemek

I: Sorunun bağlamının kategorisini belirlemek

Yukarıda verilen kategorilerden faydalanarak ikinci aşamada kullanılacak olan Süreç Takip Formunun temel eylem cümleleri oluşturulmuştur. Bu temel cümleler bir ölçme değerlendirme uzmanı ile birlikte yorumlanmış ve öğretmen adaylarını problem yazma sürecinde Patáková (2013) tarafindan belirtilen hedefe yönelik kasıtlı fikirlere yönlendirmek için aşağıda verilen iki eylem cümlesi de Süreç Takip Formuna eklenmiştir. Bu cümlelere $\mathrm{J}$ ve $\mathrm{K}$ kodları verilmiştir.

J: Sorunun kullanılabileceği/ölçebileceği geleneksel matematik konu alanını/alanlarını belirlemek

$\mathrm{K}$ : Sorunun matematik okuryazarlığına uygunluğunu değerlendirmek

Tüm bu işlemler sonucunda “verilerin analizi” başlığı altında Şekil 1'de sunulan ve toplam 11 eylem cümlesini içeren Süreç Takip Formu oluşturulmuştur. Öğretmen adaylarının problem yazma sürecinde izledikleri sıralamayı etkilememek için eylemler bu formda rastgele dizilmiştir ve bu nedenle rastgele dizildiği öğretmen adaylarına ikinci aşama öncesinde ifade edilmiştir.

Araştırmanın ikinci sorusu öğretmen adaylarının matematik okuryazarlığı problem yazma sürecinde yürüttükleri bu eylemlerin sıklıkla nasıl sıralandığını belirlemeyi gerektirmektedir. Yöntemin ikinci aşamasında, ikinci çalışma grubunun Süreç Takip Formlarına göre, bir duraktan diğerine kaç kez geçildiği, bu geçişlerde varış durağının kaçıncı sırada olduğu ve sıra ortalaması Tablo 3 'te sunulmuştur. 
Tablo 3.

Duraklar Arası Geçişlere İlişkin Veriler

\begin{tabular}{|c|c|c|c|c|c|c|c|}
\hline $\begin{array}{l}\text { Önceki } \\
\text { Durak }\end{array}$ & $\begin{array}{l}\text { Varış } \\
\text { Durağ1 } \\
\text { (V.D.) }\end{array}$ & $\begin{array}{l}\text { Tekrar } \\
\text { Sayısı }\end{array}$ & $\begin{array}{l}\text { V.D. Sira } \\
\text { Ortalaması }\end{array}$ & $\begin{array}{l}\text { Önceki } \\
\text { Durak }\end{array}$ & $\begin{array}{l}\text { Varış } \\
\text { Durağ1 } \\
\text { (V.D.) }\end{array}$ & $\begin{array}{l}\text { Tekrar } \\
\text { Sayıs1 }\end{array}$ & $\begin{array}{l}\text { V.D. Sira } \\
\text { Ortalamas }\end{array}$ \\
\hline A & B & 20 & 4,1 & F1:EVT & $\mathrm{J}$ & 7 & 11,2 \\
\hline A & $\mathrm{C}$ & 15 & 5,33 & F1:EVT & K & 10 & 10,9 \\
\hline A & D & 5 & 3,8 & G1:HYR & B & 5 & 7,8 \\
\hline A & $\mathrm{E}$ & 2 & 5 & G1:HYR & $\mathrm{C}$ & 2 & 9 \\
\hline A & G1:EVT & 3 & 6,66 & G1:EVT & F1:EVT & 6 & 9,33 \\
\hline A & $\mathrm{H}$ & 1 & 11 & G2:EVT & F1:EVT & 1 & 8 \\
\hline A & I & 2 & 4,5 & G1:EVT & $\mathrm{H}$ & 21 & 9,33 \\
\hline A & $\mathrm{J}$ & 1 & 5 & G2:EVT & $\mathrm{H}$ & 4 & 12,75 \\
\hline A & K & 1 & 13 & G1:EVT & I & 2 & 8 \\
\hline B & A & 17 & 5,11 & G1:EVT & $\mathrm{J}$ & 2 & 8 \\
\hline B & $\mathrm{C}$ & 20 & 5,35 & G1:EVT & K & 5 & 7,8 \\
\hline B & D & 2 & 4 & G2:EVT & $\mathrm{K}$ & 1 & 11 \\
\hline B & $\mathrm{E}$ & 6 & 5,83 & $\mathrm{H}$ & B & 1 & 8 \\
\hline B & G1:EVT & 1 & 10 & $\mathrm{H}$ & F1:EVT & 31 & 10,8 \\
\hline B & G2:EVT & 3 & 9,33 & $\mathrm{H}$ & F2:EVT & 1 & 16 \\
\hline B & $\mathrm{J}$ & 2 & 5 & $\mathrm{H}$ & F1:HYR & 1 & 10 \\
\hline B & K & 4 & 7,75 & $\mathrm{H}$ & G1:EVT & 2 & 7,5 \\
\hline $\mathrm{C}$ & A & 6 & 5 & $\mathrm{H}$ & $\mathrm{J}$ & 1 & 8 \\
\hline $\mathrm{C}$ & B & 7 & 5,14 & $\mathrm{H}$ & $\mathrm{K}$ & 2 & 9,5 \\
\hline $\mathrm{C}$ & D & 3 & 5,33 & I & A & 8 & 3,25 \\
\hline $\mathrm{C}$ & $\mathrm{E}$ & 8 & 5,37 & I & B & 10 & 3,3 \\
\hline $\mathrm{C}$ & G1:EVT & 9 & 7,55 & I & $\mathrm{C}$ & 2 & 4,5 \\
\hline $\mathrm{C}$ & G2:EVT & 2 & 11 & I & D & 2 & 2 \\
\hline $\mathrm{C}$ & G1:HYR & 3 & 6,66 & I & $\mathrm{E}$ & 5 & 3,8 \\
\hline $\mathrm{C}$ & $\mathrm{H}$ & 2 & 8,5 & I & G1:EVT & 2 & 7,5 \\
\hline $\mathrm{C}$ & I & 2 & 6 & I & $\mathrm{J}$ & 9 & 6 \\
\hline $\mathrm{C}$ & J & 2 & 6 & I & $\mathrm{K}$ & 3 & 11 \\
\hline $\mathrm{C}$ & K & 9 & 7,66 & $\mathrm{~J}$ & A & 4 & 5 \\
\hline D & A & 6 & 2,16 & $\mathrm{~J}$ & B & 2 & 7,5 \\
\hline $\mathrm{D}$ & B & 5 & 2,2 & $\mathrm{~J}$ & $\mathrm{C}$ & 3 & 6,66 \\
\hline D & $\mathrm{C}$ & 2 & 4 & $\mathrm{~J}$ & D & 1 & 2 \\
\hline $\mathrm{D}$ & $\mathrm{E}$ & 6 & 3,83 & $\mathrm{~J}$ & $\mathrm{E}$ & 2 & 4 \\
\hline D & G1:HYR & 1 & 5 & $\mathrm{~J}$ & F1:EVT & 1 & 9 \\
\hline D & I & 24 & 2,54 & $\mathrm{~J}$ & G1:EVT & 6 & 8 \\
\hline D & J & 3 & 4,33 & $\mathrm{~J}$ & $\mathrm{H}$ & 6 & 9 \\
\hline E & A & 5 & 3,8 & $\mathrm{~J}$ & I & 2 & 9,5 \\
\hline E & B & 3 & 5,66 & $\mathrm{~J}$ & K & 8 & 9,75 \\
\hline E & $\mathrm{C}$ & 4 & 7,25 & K & B & 1 & 9 \\
\hline E & D & 1 & 5 & K & $\mathrm{C}$ & 2 & 9 \\
\hline E & G1:EVT & 4 & 7 & K & E & 1 & 8 \\
\hline $\mathrm{E}$ & $\mathrm{H}$ & 3 & 8,33 & K & F1:EVT & 4 & 10,25 \\
\hline E & I & 6 & 4,5 & K & G1:EVT & 10 & 9,6 \\
\hline E & $\mathrm{J}$ & 3 & 4,66 & K & G1:HYR & 3 & 8,33 \\
\hline E & K & 2 & 7 & K & G2:EVT & 1 & 14 \\
\hline F1:HYR & B & 1 & 11 & $\mathrm{~K}$ & $\mathrm{H}$ & 1 & 8 \\
\hline F1:EVT & $\mathrm{C}$ & 1 & 12 & $\mathrm{~K}$ & I & 1 & 6 \\
\hline \multirow{2}{*}{ F1:EVT } & $\mathrm{H}$ & 1 & 10 & $\mathrm{~K}$ & $\mathrm{~J}$ & 6 & 8,16 \\
\hline & Toplam: & 239 & & & Toplam: & 211 & \\
\hline
\end{tabular}


Tablo 3 çalışmada elde edilen duraklar arası tüm geçişleri (toplam 450 geçiş) içermektedir. Tablo 3'te D'den I'ya 24 kez geçildiği ve bu geçişlerde varış durağ 1 olan I'nın sıra ortalamasının 2.54 olduğu görülmektedir. Bir varış durağının sırasının en az 2 olabileceği düşünüldüğünde D'den I’ya geçişlerin soru yazma sürecinin başlangıcında yer alma olasılığının yüksek olduğu anlaşılmaktadır.

Tablo 3'e göre en sık tekrar edilen geçişin 31 tekrar sayısı ile H durağından F1:EVT durağına yapıldığı anlaşılmaktadır. Burada varış durağı olan F1:EVT'nin sıra ortalamasının 10.8 olması, bu geçişe soru yazma sürecinin sonlarına doğru yer verildiğini göstermektedir.

Tablo 3'teki verileri tamamlamak için soru yazma sürecinde her bir durağın kaç kez ilk ve son durak olduğunu gösteren Tablo 4 oluşturulmuştur. Tablo 4 'te verilen toplam geliş ve toplam gidiş sayıları (450) ile Tablo 3'te verilen toplam geçiş sayılarının (tekrar sayısı 239+211) eşit olması çalışmanın güvenirliğini (iç tutarlılığını) göstermektedir. Ayrıca Tablo 4'te verilen ilk durak olma durumu ve son durak olma durumu sayıları ile çalışmada değerlendirilen Süreç Takip Formu sayısının eşit olması çalışmanın güvenirliğini (iç tutarlılığını) göstermektedir.

Tablo 4.

Duraklara İlişkin Veriler

\begin{tabular}{|c|c|c|c|c|}
\hline Durak & $\begin{array}{c}\text { Durağa Geliş } \\
\text { Sayısı }\end{array}$ & $\begin{array}{c}\text { Duraktan Gidiş } \\
\text { Sayısı }\end{array}$ & $\begin{array}{c}\text { İlk Durak Olma } \\
\text { Durumu }\end{array}$ & $\begin{array}{c}\text { Son Durak Olma } \\
\text { Durumu }\end{array}$ \\
\hline $\mathrm{A}$ & 46 & 50 & 4 & \\
\hline B & 55 & 55 & & \\
\hline $\mathrm{C}$ & 51 & 53 & 3 & 1 \\
\hline D & 14 & 47 & 33 & \\
\hline $\mathrm{E}$ & 30 & 31 & 1 & \\
\hline F1:EVT & 43 & 19 & & 24 \\
\hline F1:HYR & 1 & 1 & & \\
\hline F2:EVT & 1 & 0 & & 1 \\
\hline G1:EVT & 37 & 36 & & 1 \\
\hline G1:HYR & 7 & 7 & & \\
\hline G2:EVT & 6 & 6 & & \\
\hline $\mathrm{H}$ & 39 & 39 & & \\
\hline I & 39 & 41 & 2 & \\
\hline $\mathrm{J}$ & 36 & 35 & 1 & 2 \\
\hline K & 45 & 30 & & 15 \\
\hline Toplam: & 450 & 450 & 44 & 44 \\
\hline
\end{tabular}

Tablo 4'te en sık tercih edilen ilk durağın D olduğu görülmektedir. Toplam 44 soru yazma sürecinden 33'üne D ile temsil edilen eylemle başlanmıştır. Bu veri, yukarıda Tablo 3'e göre yapılan “D'den I'ya geçişin soru yazma sürecinin başlangıcında yer alma olasılığının yüksek olduğu" yorumunu güçlendirmektedir.

Tablo 4'te en sik tercih edilen son durağın F1:EVT olduğu görülmektedir. Toplam 44 soru yazma sürecinden 25'i F1:EVT ile temsil edilen eylemle 
sonlanmıştır. Bu veri, yukarıda Tablo 3'e göre yapılan "H'den F1:EVT'ye geçişin soru yazma sürecinin sonlarına doğru yer alma olasıllğının yüksek olduğu" yorumunu güçlendirmektedir.

Eylemlerin (i) tekrar sayllarl, (ii) sira ortalamalarl, (iii) ilk ve (iv) son durak olma durumlarına ilişkin Tablo 3 ve Tablo 4'te yer alan verilere göre iki farklı matematik okuryazarlığı problem yazma süreç şeması elde edilmiştir. Şemalar Şekil 2 'de sunulmuştur.

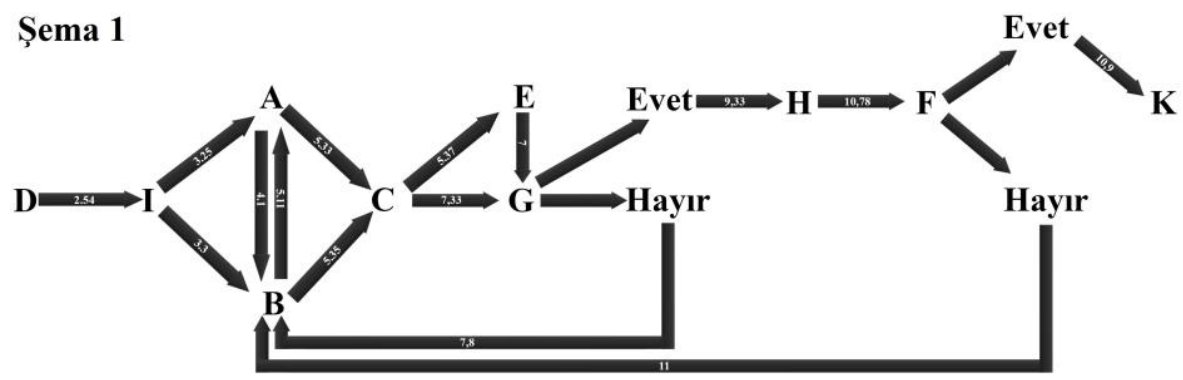

Şema 2

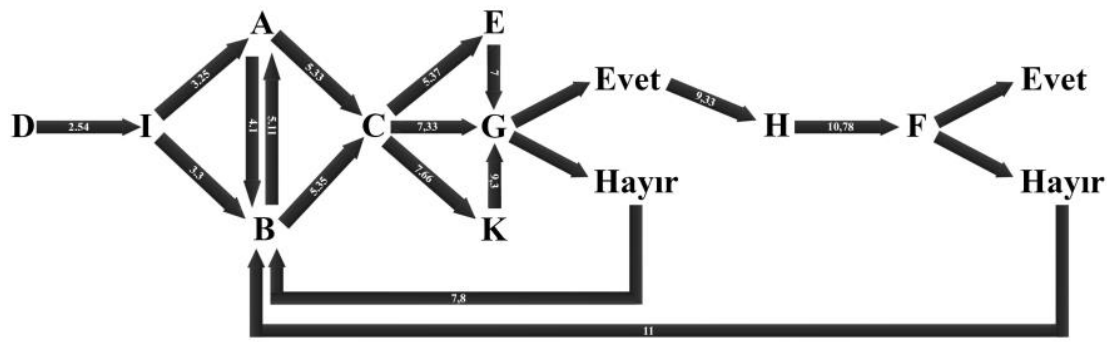

* “G1:Evet" ve "G1:Hayır" yanıtlarının verildiği her iki durumda da varış durağı "G" dir. Bu nedenle "G" nin varış durağı olduğu durumlarda sıra ortalamaları buna göre hesaplanmıștır.

* "F1:Evet" ve "F1:Hayır" yanıtlarının verildiği her iki durumda da varış durağı "F" dir. Bu nedenle "F" nin varış durağı olduğu durumlarda sıra ortalamaları buna göre hesaplanmıştır.

Şekil 2.Eylemlerin kestirilen sıralarına göre oluşturulan matematik okuryazarlı̆ğ1 soru yazma süreç şemaları

Süreç şemalarında okların içine yazılan sayılar ilgili varış durağının sıra ortalamasıdır. Süreç ilerledikçe bu sıra ortalamalarının artması beklenir. Şemalardaki bulguların bu beklentiyi karşıladığı görülmektedir.

Şekil 2'de verilen her iki süreç şemasında 10'ar eylemin sıralandığ görülmektedir. Bu şemalarda "J: Sorunun kullanılabileceği/ölçebileceği geleneksel matematik konu alanını/alanlarını belirlemek" eylemi yer almamaktadır. Bunun iki nedeni vardır. Birincisi, $\mathrm{J}$ durağının diğer duraklara geliş ve gidiş tekrar sayılarının 
birbirine çok yakın olması, diğer bir ifadeyle $\mathrm{J}$ durağından geçişlerde tekrar sayılarının yığıldığı bir durağın belirlenememesidir. İkincisi J'nin varış durağı olduğu geçişlerde J'nin sıra numarasının çok fazla değişkenlik göstermesidir. Bu iki nedenden dolayı J durağı için süreç şemasında bir yer kestirilememiştir.

\section{Tartışma, Sonuç ve Öneriler}

Matematik öğretmen adaylarının matematik okuryazarlığı soru yazma sürecinde 9 eylem gerçekleştirdiği belirlenmiştir. Öğretmen adaylarının soru yazma sürecinde, Patáková'nın (2013) çalışmasında yer verdiği "hedefe yönelik kasıtlı fikirlerle" ilerlemelerini sağlamak amacıyla "J: Sorunun kullanılabileceği/ölçebileceği geleneksel matematik konu alanını/alanlarını belirlemek" ve "K: Sorunun matematik okuryazarlığına uygunluğunu değerlendirmek" şeklinde iki eylem de bu çalışmada bulunan 9 eylemin üzerine eklenerek 11 eylem cümlesinden oluşan "Süreç Takip Formu" oluşturulmuştur. Bu formlarla gözlenen soru yazma süreçlerinde J'nin dışındaki 10 eylemin yeri kestirilebilmiş ve Şekil 2'deki süreç şemalarında sunulmuştur.

Şekil 2'de yer verilen eylemler Pelczer ve Gamboa'nın (2009) kurulum, dönüşüm, formülasyon, değerlendirme ve son değerlendirmeyi içeren birbirinden ayrıştırılması ve sıralanması şart olmayan beş aşamalı modeli ile benzerlik göstermektedir. Bu çalışma sonucunda elde edilen;

- "D: Bağlamı belirlemek" ve I: "Sorunun bağlamının kategorisini belirlemek" eylemleri "Kurulum" aşaması ile,

- "A: Soruda verilecekleri ve istenecekleri belirlemek", "B: Matematiksel verileri belirlemek", "C: Taslak soru metnini (varsa şekille beraber) oluşturmak", "E: İhtiyaç varsa, bağlama göre sınırlandırmaları ve varsayımları belirlemek" eylemleri "Kurulum", "Formülasyon" ve "Dönüşüm" aşamaları ile,

- “G: Sorunun çözümünü adım adım yazmak ve doğruluğunu kontrol etmek” eylemi "Değerlendirme" aşaması ile,

- "H: Soru metnini grup dışında birine vererek (ona soru ile ilgili hiçbir açıklama yapmadan) çözmesini istemek" ve "F: Farklı gruptan birinin çözümü ile soru yazarlarının çözümünü karşılaştırmak" eylemleri "Son Değerlendirme" aşaması ile örtüşmektedir.

Soru yazma sürecinde " $F$ " veya " $G$ " duraklarında yapılan değerlendirmelerin sonucunun olumsuz (Hayır) çıktığı durumlarda öğretmen adaylarının sıklıkla "B: Matematiksel verileri belirlemek" durağına geri döndüğü görülmektedir. Bu durum öğretmen adaylarının başlangıçta belirledikleri bağlamdan (fikirlerinden) kolayca vazgeçmediklerini göstermektedir. Bu ise öğretmen adaylarının bağlam belirleme aşamasında deneyimli soru yazarları gibi (Patáková, 2013) kasıtlı veya kısmen kasıtlı fikirlere yer vermiş olduklarının bir göstergesi olabilir. Bunun, soru yazmaya 
başlamadan önce aldıkları 8 (13-5) haftalık soru yazma eğitiminden kaynaklandığı söylenebilir.

Demir ve Altun (2018) yaptıkları çalışmada soru yazma sürecinin ilk dakikalarında tartışmaların genellikle bir bağlama karar verilmesinin üzerine yoğunlaştığını belirtmiştir. Bu çalışmada da soru yazma süreç şemalarında (Şekil 2) bağlamın belirlenmesi eyleminin ilk sırada yer aldığı görülmektedir. Bu açıdan bu iki çalışmanın sonuçları birbirini desteklemektedir.

Bu çalışmada tüm eylemlerin belirlenmesi olasılığını artırmak için 112 öğretmen adayının gruplar halinde soru yazma süreçlerinin incelenmesi tercih edilmiştir. Soru yazma süreci hakkında daha derinlemesine incelemelerin yapılabileceği, sınırlı sayıda katılımcının mülâkat, sesli-görsel materyallerle kayıt ve benzeri teknikler kullanılarak soru yazma sürecinin araştırıldığı çalışmalar yapılabilir.

Bu çalışmada ortaya konan matematik okuryazarlığı soru yazma sürecinde yer alan eylemlerin ve bunlara ilişkin süreç şemalarının belirlenmesinin, problem yazma sürecinin nasıl işlediğine ilişkin henüz sınırlı düzeyde (Silber ve Cai, 2017) olan bilgi birikimine katkı sağlayacağı düşünülmektedir. Bu şemalar sistematik bir soru yazma süreci geliştirilmesine ilişkin bir ilk adım olarak görülebilir. Sistematik soru yazma süreçleri öğretmen ve öğretmen adaylarının bu konuda daha hızlı deneyim kazanmalarına, problem yazmada yaşadıkları güçlüklerin azaltılmasına (Stickles, 2011) katkı sağlayabilir.

\section{Kaynakça}

Cai J, Hwang S. (2002). Generalized and generative thinking in US and Chinese students' mathematical problem solving and problem posing. The Journal of Mathematical Behavior,21, 401-421.

Chmiliar, L. (2010). Multiple-case designs. In A. J. Mills, G. Eurepas \& E. Wiebe (Eds.), Encyclopedia of case study research (pp 582-583). USA: SAGE Publications.

Crespo, S. (2003). Learning to pose mathematical problems: Exploring changes in preservice teachers' practices. Educational Studies in Mathematics,52, 243-270.

Demir, F. \& Altun, M. (2018). Matematik Okuryazarlığı Soru Yazma Süreç ve Becerilerinin Gelişimi. Eğitim ve Bilim, 43(194), 19-41.

Demir, F., Altun, M. \& Köse, M. (2018). Matematik öğretmen adaylarının matematik okuryazarlı̆̆ soru yazma becerilerinin geliştirilmesi ve değerlendirilmesi. Yükseköğretim Kurumları (DPÜ) Tarafından desteklenen Bilimsel Araştırma Projesi, 2015-100.

Goldenberg, E. \& Walter, M. (2003). Problem posing as a tool for teaching mathematics. In H. L. Schoen \& R. I. Charles (Eds.), Teaching mathematics 
through problem solving (pp. 55-67). Reston, VA: National Council of Teachers of Mathematics, Inc.

Hancock, R.D. \& Algozzine, B. (2006). Doing Case Study Research. New York: Teachers College Press.

McCrone, S.S. \& Dossey, J.A. (2007). Mathematical literacy-it's become fundamental. Principal Leadership, 7(5), 32-37.

National Council of Teachers of Mathematics. (1991). Professional standards for teaching mathematics. Reston, VA: Author.

National Council of Teachers of Mathematics. (2000). Principles and standards for school mathematics. Reston, VA: Author.

National Governors Association Center for Best Practices and Council of Chief State School Officers. (2010). Common core state standards for mathematics. Washington (DC): NGA.

Organisation for Economic Co-Operation and Development, (2013). PISA 2015 draft mathematics framework. OECD Publishing.

Organisation for Economic Co-Operation and Development, (2016). PISA 2015 assessment and analytical framework. Science, reading, mathematics and financial literacy. Paris: OECD Publishing.

Patáková, E. (2013) Teachers' problem posing in mathematics. Procedia - Social and Behavioral Sciences 93, $836-841$.

Pelczer, I., \& Gamboa, F. (2009). Problem posing: Comparison between experts and novices. M. Tzekaki, M. Kaldrimidou, \& C. Sakonidis (Eds.), Proceedings of the 33th International Conferrence of the International GroupforthePsychology of MathematicsEducation, (pp. 353 360). Thessaloniki, Greece: PME.

Silber, S. \& Cai, J. (2017). Pre-service teachers' free and structured mathematical problem posing. International Journal of Mathematical Education in Science and Technology, 48(2), 163-184, DOI: 10.1080/0020739X.2016.1232843.

Stickles, P.R. (2011). An analysis of secondary and middle school teachers' mathematical problem posing. Investigations in Mathematics Learning, 3(2), 134, DOI: 10.1080/24727 466.2011.11790301.

Stoyanova E, Ellerton N. F. (1996). A framework for research into students' problem posing in school mathematics. In Clarkson PC, (Ed), Technology in mathematics education. Mathematics Education Research Group of Australasia, The University of Melbourne, 518-525.

Vacc, N.N. (1993). Implementing the "Professional standards for teaching mathematics": questioning in the mathematics classroom. Arithmetic Teacher, $41,88-91$. 
Van Harpen, X.Y. \& Sriraman, B. (2013). Creativity and mathematical problem posing: an analysis of high school students' mathematical problem posing in China and the USA. Educational Studies in Mathematics, 82, 201-221.

Yıldırım, A. ve Şimşek, H. (2008). Sosyal bilimlerde nitel araştırma yöntemleri (7. bs.). Ankara: Seçkin Yayıncılık.

Yuan X. \& Sriraman B. (2011). An exploratory study of relationships between students' creativity and mathematical problem-posing abilities. In B. Sriraman \& K.H. Lee (Eds.), The elements of creativity and giftedness in mathematics. Rotterdam (Netherlands): Sense Publishers, 5-28.

\section{Extended Abstract}

In this study, the problem posing processes of mathematics teacher candidates were examined. At the end of the study, it was aimed to determine the actions managed by the candidates in the problem posing process and in which order these actions were frequently followed. In other words, the aim of the study was to determine whether or not there were systematic problem posing processes carried out by the candidates. Systematic processes can contribute to the development of more qualified problem posing activities and can reduce the difficulties that teacher candidates face in posing problems. Furthermore, in future studies guided by the systematic processes obtained from this study, it can be ensured that candidate teachers give more place to intentional (target-oriented) actions and gain experience faster even if they are inexperienced at posing problems.

Mathematical literacy problems are the subsets of mathematical problems and there are few studies examining the problem posing process in this field. Mathematical literacy is defined as the capacity of the individual to formulate, implement, and interpret mathematics in various ways in living environments (OECD, 2013; 2016). By this definition of mathematical literacy, problems are presented in contexts from real life. Teacher candidates have described "writing an event / a situation they experienced as a question" (Demir and Altun, 2018) and "writing questions by observing the events in daily life" (Demir, Altun, Köse, 2018) as an opportunity in the process of posing mathematical literacy problems. Also, it has been stated that these situations increase the teacher candidates' interest in posing problems. In this study, teacher candidates were asked to pose mathematics literacy problems with the thought that these relevant opportunities could reduce the difficulties faced by teacher candidates and increase their interest in posing problems as well as contribute to filling the gap in the matter of posing problems. There are other reasons why the study focused particularly on mathematical literacy problems. Mathematical literacy is understanding the role of mathematics in real life and using mathematics to solve problems that people face (McCrone and Dossey, 2007). It has been thought that if teacher candidates' successfuly managed the process of posing mathematics literacy problems it would help them to realize the relationship between 
mathematics and real life and make their students realize this relationship in the future.

The aim of this study was to determine the actions on the process of posing problems posing in mathematical literacy and in which order these actions were frequently followed. The studies carried out to achieve the aim consisting of two stages. Qualitative research methods have been used in the operation of these stages and this study can be defined as a qualitative case study. Two different study groups participated in the study in two different academic years. The first group consisted of 47 and the second group consisted of 65 primary school math teacher candidates. With the data obtained from the first study group, the actions involved in the process of mathematical literacy problem posing were determined. Thereafter, a process monitoring form was created from these actions. Through the process monitoring form, it was determined with the data obtained from the second study group how the actions involved in the process of mathematic literacy problem posing were ordered frequently.

It has been determined that there are nine actions in the process of mathematics literacy problem posing: "(A) determining what will be given and what will be asked in the question, (B) determining the mathematical data, (C) creating the draft question text (with figures, if applicable), (D) determining the context, (E) determining the limitations and assumptions according to the context if the need arises, $(F)$ comparing the answer of someone from the different group with the answer of the question writer, $(\mathrm{G})$ writing the answer of the question step by step and checking its accuracy, $(\mathrm{H})$ giving the question text to someone outside the group (without giving him/her any explanation about the question) and wanting him/her to answer it, (I) determining the category of the context of the question". As a result of the expert opinions which are taken in order to ensure that teacher candidates move forward with "the target-oriented intentional ideas" included in the study of Patáková (2013), Process Monitoring Form is created with the addition of two other actions as follows: "(J) identifying the traditional mathematics subject area(s) where the question can be used/measured, $(\mathrm{K})$ assessing the appropriateness of the problem to mathematical literacy". Data related to the actions' (i) repetition numbers, (ii) mean of the order, being (iii) first and (iv) last stop have been obtained from the process monitoring forms. The orders of 10 actions with the exception of $\mathbf{J}$ could be predicted in the problem posing processes observed with the Process Monitoring Forms and accordingly, two different process charts were presented in the findings.

Actions that are determined to be in the process of problem posing according to this study are similar to the five-stage model of Pelczer and Gamboa (2009), including setup, transformation, formulation, evaluation, and final assessment stages which do not have to be separated from each other or to be ordered, just as in the study of Patáková (2013). Demir and Altun (2018) stated in their study that in the first minutes of the problem posing process, discussions generally focuse on making a 
context decision. Also in this study, it is seen that the action of determining the context takes the first place in the problem posing process charts. In this respect, the results of these two studies support each other. It has been thought that determining the actions and process charts in mathematics literacy problem posing process in this study will contribute to the limited knowledge of how problem posing process works (Silber and Cai, 2017). These charts can be seen as the first step to develop a systematic problem posing process. Systematic problem posing processes can help teachers and teacher candidates to gain experience faster on this matter and reduce the difficulties they have in posing problems (Stickles, 2011). 